\title{
ASPECTOS CONTROVERTIDOS DA SENTENÇA NAS AÇÕES COLETIVAS
}

\section{CONTROVERSIAL ASPECTS OF SENTENCE IN COLLECTIVE ACTION}

\author{
Indianara Pini Sonni \\ Luiz Fernando Bellinetti'
}

\begin{abstract}
Resumo: A tutela jurisdicional coletiva gera inúmeras controvérsias no âmbito da doutrina, que vem dedicando árduos estudos no sentido de dirimir tais polêmicas, e apresentar, por conseguinte, soluções viáveis e aptas a instrumentalizar o processo, cujo objeto é direito transindividual, e assim, efetivar a tutela dos interesses plurisubjetivos. A sentença, que no aspecto da jurisdição coletiva, possui a mesma conceituação e naturezas nas ações individuais, apresenta tão somente algumas particularidades, devido ao caráter do direito tutelado, que, por óbvio, revela características diversas. Em cada ação coletiva típica, a sentença apresenta uma roupagem específica, de acordo com a tutela que a demanda destina ao direito postulado: $\mathrm{Na}$ ação civil pública, há o caráter mandamental, condenatório e executivo, a teor dos dispositivos 11 e 13 da Lei 7.347/85, ao passo que, na ação popular, há o efeito desconstitutivo/negativo além do condenatório (este deve constar na sentença, independente se for pleiteado pelo autor - trata-se de uma previsão legal, uma peculiaridade dessa ação coletiva, que decorre da relevância do direito tutelado). Por sua vez, no mandado de segurança coletivo, ao lado do efeito mandamental, deve estar acoplado outra eficácia, para que possa, assim, consubstanciar efetividade no julgado.
\end{abstract}

Palavras-chave: Tutela Coletiva. Sentença. Efeitos. Direitos Transindividuais.

Abstract: The jurisdictional protection generates countless controversies
in the scope of the doctrine, which has been devoting intense studies
in order to solve such controversies, and present, therefore, suitable
and viable solutions to instrumentalize the process, whose object is
supraindividual law, and thus effect the protection of plurisubjective
interests. The sentence, in the aspect of the collective jurisdiction, has
the same concept and nature in the individual lawsuits, has only some
features, due to the character of the protected right, which clearly shows
different characteristics. In each typical class action lawsuit, the sentence

Graduada em Direito pela Universidade do Norte do Paraná e Pós - Graduada em Direito Constitucional pela P.U.C.- Londrina (Lato Sensu). Atualmente é advogada e consultora empresarial, Mestre em Direito pela Universidade Estadual de Londrina (Direito Negocial - Processo Civil). Email: indianara pini@yahoo.com.br.

"Doutor em Processo Civil pela Pontifícia Universidade Católica de São Paulo (PUCSP); professor do Curso de Graduação em Direito e do Programa de Mestrado em Direito Negocial, da Universidade Estadual de Londrina (UEL). Email: luizbel@uel.br. 
has a specific feature in accordance with the protection the demand addresses to the right postulate: In the public civil action, there is the writ, conviction and enforcement (executive), a teor dos dispositives 11 and 13 of Law 7.347/85, while in the class action, there is the effect desconstitutive/ negative addition to the damning (this should include the sentence, regardless if it is led by the author - this is a legal provision, a peculiarity of this class action, which follows the relevance of the protected right. This way, the injunction and the writ must be given another effectiveness, thus substantiate the effectiveness trial.

Key-words: Jurisdictional protection. Sentence. Effects. Transindividual rights.

\section{INTRODUÇÃO}

O foco deste trabalho está destinado à sentença, mas não considerando tal provimento como mero instituto processual, mas sim, os aspectos controvertidos que gera no âmbito da tutela jurisdicional coletiva.

Nesse aspecto, relevante ressaltar que na esfera das ações coletivas, a sentença, em si, não provoca acentuadas controvérsias, pelo menos não na mesma intensidade que a coisa julgada, a qual vem sendo objeto de estudo de vários doutrinadores, a exemplo de Rodolfo de Camargo Mancuso, que destinou uma obra específica ao tema (Jurisdição Coletiva e Coisa Julgada).

Dessa forma, como a coisa julgada é uma qualidade da sentença, que se manifesta de acordo com os seus mais diversos efeitos, mister se faz discorrer acerca do ato decisório na seara da tutela dos interesses transindividuais, declinando as decorrências relevantes em cada modalidade de ações coletivas, como natureza jurídica e efeitos secundários, bem como descrevendo as peculiaridades da sentença, as quais se justificam pelas características reinantes no interesse tutelado.

\section{SENTENÇA NAS AÇÕES COLETIVAS: ASPECTOS GERAIS}

A sentença, com a nova sistemática processual civil, mas especificamente com o advento da lei n.ำ11.232/2005, que dedicou nova redação ao artigo 162, $\S 1^{a}$ do Código de Processo Civil, é definida pelo referido dispositivo como ato do juiz que acarreta em alguma das situações previstas nos arts. 267 (que trata da extinção do processo sem resolução de mérito) e 269 (casos em que implica na análise do mérito). Contudo, antes de 2005, a sentença era conceituada como o ato do juiz que põem fim ao processo, decidindo ou não o mérito da causa.

A sentença é o meio de efetivar a tutela efetivamente prestada. Para tanto, 
tal meio deve estar previsto na legislação processual. A sentença é apenas uma resposta do legislador, atento a necessidade de efetivar um processo civil capaz de tutelar os direitos.

Assim, relevante salientar que sentença diferencia-se de tutela. Para o ingresso de uma demanda em juízo, é necessário conhecer a natureza do direito material e as tutelas que lhe são cabíveis, para posteriormente, verificar quais as sentenças e os meios de execução coerentes com uma efetiva prestação jurisdicional.

No âmbito da tutela jurisdicional coletiva, inicialmente, é importante relatar que a sentença pode ter qualquer uma das eficácias previstas no processo individual. Assim, poderá ser (classificação quinaria):

- meramente declaratória ou declaratória stricto sensu que é aquela que declara a existência, ou a inexistência, ou mesmo o modo de ser de uma relação jurídica. Nos dizeres de Marinoni, (2006, p. 425) "todas as sentenças contêm declaração" e "toda sentença traz ínsito o efeito declaratório" (LENZA, 2003, p. 317).

- constitutiva que é aquela que pode criar, modificar ou extinguir uma relação jurídica.

- condenatória que abre oportunidade para uma execução forçada.

- mandamental, caracterizada por dirigir uma ordem para coagir o réu. Nos dizeres de Lenza (2003, p. 328) "implica o cumprimento específico da ordem do juiz, sob pena de ser configurar crime de desobediência ou de responsabilidade". Em tal provimento, inexiste condenação, porém há uma ordem, surgindo, desse comando mandamental, severas consequências em caso de descumprimento.

Tendo em vista essa perspectiva das ações mandamentais, há uma crítica severa por parte de algum dos doutrinadores (LENZA, 2003, p. 329), no que tange ao veto exarado no art. 85 do CDC, o qual permitia o ajuizamento de ação mandamental, atendendo-se as normas concernentes ao mandado de segurança, contra atos ilegais de pessoas físicas ou jurídicas, que lesassem direito líquido e certo, individual, coletivo ou difuso.

Não obstante a tal veto, no diploma protetivo do consumidor, há o art. 83, que assegura toda e qualquer espécie de ação capaz de propiciar a adequada e efetiva tutela dos direitos e interesses protegidos pelo código. Assim, não há como contestar a possibilidade das ações mandamentais para evidenciar a tutela dos direitos coletivos.

- executiva: "são aquelas que contêm, além da autorização para executar (tal como ocorre na sentença condenatória) aptidão intrínseca para levar 
a efetiva satisfação do credor, independentemente de nova demanda de execução" (WAMBIER, 2007, p. 507).

O fundamento de tal classificação de sentenças, no aspecto da tutela dos direitos supra-individuais, é o dispositivo $84, \S 5^{\underline{a}}$ do CDC, o qual disciplina que "o juiz poderá determinar as medidas necessárias para obtenção do resultado prático equivalente,” exemplificando algumas providências.

Assevera Marinoni (2006, p. 735) que "a sentença mandamental e executiva, bem como os meios de execução adequados a tutela do meio ambiente saudável (por exemplo) estão previstas no art. 84 do CDC.”

Por oportuno ressaltar, todavia, que parte da doutrina, no caso das ações coletivas, entende que a sentença mandamental e a executiva não possui tamanha relevância, contudo, como ressalta o autor acima citado (MARINONI, 2006, p. 734), "podem ser úteis e necessárias diante de determinados casos concretos." O referido autor preleciona, como exemplo, "a necessidade de anulação de contrato lesivo ao meio ambiente."

A tutela jurisdicional transindividual se concentra, principalmente, na Ação Popular, Ação Civil Pública, Mandado de Segurança Coletivo e no Controle Concentrado de Constitucionalidade, por meio de ADIN e ADECON. Contudo, o presente apanhado se concentrará nos reflexos da sentença nas três primeiras modalidades descritas.

\section{SENTENÇA NA AÇÃO CIVIL PÚBLICA}

A sentença, no âmbito da ação civil pública, não possui particularidades que acarretem discussões. Todavia, em tal decisão, o julgador deve-se atentar que o objeto é um direito transindividual, cujos titulares será uma coletividade ampla de pessoas, as quais serão, ao menos no aspecto coletivo, afetados pelo conteúdo decisório.

A particularidade relevante, que é uma decorrência lógica do interesse tutelado, é que em tal sentença deverá perdurar uma característica genérica, o que não ocorre (ou dificilmente acontece), na decisão oriunda de um processo individual.

Também remanesce uma outra característica no que tange ao pedido e a causa de pedir. O art. 293 do CPC determina que a interpretação do pedido deverá ser restritiva, "interpretar restritivamente o pedido é tirar dele tudo quanto nele se contém, e só o que nele se contém, sem que se possa ampliá-lo por força da interpretação extensiva...” (PASSOS apud DIDIER/ZANETTI. 2009, p. 288), o que não ocorre na seara da tutela coletiva. Prelecionam os referidos autores 
(DIDIER/ZANETTI, 2009, p. 288).

O Código Modelo de Processo Coletivos para a Ibero-América adota, porém, soluções diversas para as ações coletivas: "Art. 10. Nas ações coletivas, o pedido e a causa de pedir serão interpretados extensivamente". Também essa é a solução proposta pelo CBPC-IBDP: "Art. 5ํㅡㄹ Pedido e causa de pedir - Nas ações coletivas, a causa de pedir e o pedido serão interpretados extensivamente, em conformidade com o bem jurídico a ser protegido.”

Dessa forma, visto que a sentença oriunda de uma ação civil pública terá a mesma gênese de um ato de cunho decisório no aspecto individual, importante identificar a sua natureza jurídica, com o estudo dos dispositivos atinentes aos efeitos.

\subsection{Natureza Jurídica}

Quanto à natureza jurídica da sentença proferida na ação civil pública, conforme os preceitos descritos pelo art. 11 da Lei n. ${ }^{\circ}$ 7.347/1985, depreende que pode ser mandamental e executiva.

Art. 11. Na ação que tenha por objeto o cumprimento de obrigação de fazer ou não fazer, o juiz determinará o cumprimento da prestação da atividade devida ou a cessação da atividade nociva, sob pena de execução específica, ou de cominação de multa diária, se esta for suficiente ou compatível, independentemente de requerimento do autor.

Da análise do artigo 13, por seu turno, constata-se a presença da sentença condenatória, ao determinar que.

Art. 13. Havendo condenação em dinheiro, a indenização pelo dano causado reverterá a um fundo gerido por um Conselho Federal ou por Conselhos Estaduais de que participarão necessariamente o Ministério Público e representantes da comunidade, sendo seus recursos destinados à reconstituição dos bens lesados.

Nos dizeres de Mancuso, (LEONEL apud MANCUSO 2007, p. 254), "adequação e suficiência são os critérios norteadores da delimitação da tutela coletiva."

Assim, tendo em vista a classificação quinaria das sentenças, proposta, no Ordenamento Jurídico Pátrio, por Pontes de Miranda, é relevante ponderar se a sentença, na ação civil pública, pode ser meramente declaratória, ou mesmo simplesmente constitutiva.

Como já foi acima mencionado, toda a sentença tem um conteúdo declaratório, porque reconhece, ou ao menos admite que um certo fato, ou ato existiu. Assim, para Mancuso, na ação civil pública, não é comumente ocorrer sentença com o caráter meramente declaratório. Nesse aspecto, ressalta que (MANCUSO, 2007, p. 255). 
Em que pese o crescente elestério no emprego da ação declaratória, não é comum o seu manejo para a defesa dos interesses metaindividuais: primeiro, porque a lei n.- 7347/85 não contemplou a tutela, pela ação civil pública, do interesse a mera declaração ou só eliminação de incerteza acerca de um dado interesse difuso ou coletivo, mas acenou para uma tutela francamente condenatória - caso de danos produzidos - ou ao menos cautelar - caso de danos temidos; segundo seria questionável a utilidade que um provimento só declaratório teria na espécie: no art. 11 dessa lei está dito que a sentença condenará ao réu o cumprimento da prestação da atividade devida ou a cessação da atividade nociva, nesse contexto parece não sobrar espaço para um mero reconhecimento de que o fato ocorreu ou de que a lesão se verificou, ou que o autor tem o direito a receber, em ação própria a devida reparação.

Mesmo diante da atuação mínima para a ação declaratória no âmbito das ações coletivas, há os preceitos do já reproduzido artigo 83 do CDC, que abre espaço para todas as espécies de provimentos, aptos a efetivar a tutela jurisdicional coletiva.

Quanto às sentenças meramente constitutivas, Mancuso (2007, p. 258), entende que a hipótese de sentença que apenas retire a eficácia do ato impugnado, deve ser descartada, pois, para ele, o comando condenatório deve surgir "como um corolário na desconstituição do ato ou fato sindicado.” O referido autor cita como exemplo a hipótese do art. 51 da lei 8078/90.

Dessa forma, concentrando os dois provimentos (condenatório e constitutivo) estará se atendendo ao princípio da economia processual: se o ajuste é lesivo ou injusto e se dele decorreu dano coletivo, a sentença deve ser desconstitutiva e condenatória, concomitantemente.

Em tal entendimento, inexiste contraposição no que tange ao princípio da demanda ou do dispositivo, ou mesmo aos limites da sentença, previstos pelo art. 460 do CPC. O que se quer realçar, é que no interesse de agir se inclua a utilidade, para que a tutela pleiteada possa sanar a integralidade do dano ou da ameaça ao interesse supraindividual.

\subsection{Dos Preceitos do Art. 11 da Lei 7347/85: Algumas Indagações}

A teor, ainda, do art. 11 da lei em comento, denota-se que haverá a condenação à prestação positiva ou negativa, "sob pena de execução específica ou cominação de multa diária.” Assim, a doutrina declina alguns apontamentos acerca de tais disposições.

As hipóteses previstas para compelir o réu ao cumprimento do dever determinado ("sob pena de execução específica, ou cominação de multa diária”) estão ao cargo do prudente arbítrio do juiz, o qual deve optar, na sentença, pela forma que irá proceder: o demandado deve cumprir o que 
foi prescrito (cumprimento da obrigação positiva ou negativa) sob pena de execução específica ou incidência de multa diária, a qual, ressalte-se, poderá ser fixada "independentemente de requerimento do autor." Tal disposição justifica-se diante da relevância dos interesses transindividuais, de maneira que o magistrado deve estar dotado de poderes para a consecução de uma tutela eficaz, se afastando assim de alguns estigmas processuais.

Outro questionamento oriundo do art. 11 da lei em questão concerne à multa diária prevista, a qual se trata de astreinte, e não de condenação autônoma. Nos dizeres de Mancuso, é "um meio de induzir o devedor a prestar o fato devido ou resignar-se à abstenção cominada, na pressuposição de que, bem dosado a multa, o devedor ficará desistimulado a resistir o cumprimento do julgado.” (MANCUSO, 2007, p. 266). Tem, assim, natureza coercitiva (finalidade compulsiva), atuando como elemento indutor do cumprimento do dever imposto, de maneira que, pode ultrapassar até o valor da obrigação.

Quando o julgador verificar que a fixação de multa não é uma medida eficaz, ele pode se valer das disposições do parágrafo 5ำ do art. 461 do CPC, ou outras sanções que, embora não estejam especificadas, sejam relevantes para e efetiva prestação jurisdicional, pois o rol da lei processual é meramente exemplificativo.

$\mathrm{O}$ artigo 11 acima transcrito traduz a necessidade de se criar medidas dinâmicas para que, efetivamente, os danos possam ser evitados ou corrigidos. "São instrumentos capazes de preservar, ao máximo, o bem transindividual em sua forma específica, seja preventivamente, evitando o dano, ou de forma repressiva, buscando a recomposição do status quo ante" (LENZA, 2003, p. 344).

O referido autor (LENZA, 2003, p. 344) prossegue afirmando que, dado o caráter dos direitos em tela, é preferível a imposição de certa conduta, para obter o efetivo ressarcimento, que a condenação em perdas e danos. Ressalta, ainda que.

O êxito da execução específica das obrigações de fazer depende, acima de tudo, dos instrumentos colocados a disposição das partes e do juiz, sejam aqueles que exercem influência sobre a vontade do obrigado (meios de coação), sejam aqueles que permitam o implemento do resultado pretendido sem a participação e vontade do co-obrigado (meios de sub-rogação).

Por derradeiro, importante considerar que o art. 11 prevê alternativas a ser fixadas em caso do não cumprimento voluntário, sendo elas, "execução específica ou a cominação de multa diária.” Contudo, saliente-se que, a multa não é sub-rogatória da obrigação positiva ou negativa não atendida, mas sim, um meio de coação, de compelir ao cumprimento do julgado. "Tem o juiz 
certa discricionariedade para fixar o montante da multa, podendo mesmo a distanciar-se do que veio pedido a esse título, pelo autor, se tal the parecer necessário para resguardar a finalidade coativa desejável” (MANCUSO, 2007, p. 272).

\subsection{Efeito Secundário da Sentença}

A sentença de procedência proferida na ação civil pública produz, automaticamente, "o efeito de tornar certa a obrigação do réu de indenizar os danos individuais decorrentes do ilícito civil, objeto da demanda, permitindo aos respectivos titulares do direito à reparação (vítimas e sucessores), a imediata liquidação e execução, independente de nova sentença condenatória" (ZAVASCKI, 2008, p. 82).

Tal conclusão é deduzida do art. 103 , $\S^{\circ}$ da lei $n .^{\circ}$ 8.078/90, que assim prescreve.

Os efeitos da coisa julgada de que cuida o art. 16, combinado com o art. 13 da lei 7.347 de 24 de julho de 1985, não prejudicarão as ações de indenização por danos pessoalmente sofridos, propostas individualmente ou na forma prevista neste Código, mas, se procedente o pedido, beneficiarão as vítimas e seus sucessores, que poderão proceder à liquidação e a execução, nos termos dos arts. 96 e 99.

O efeito secundário é peculiar não apenas as sentenças proferidas em ação, a qual tem como objeto alguma infração ao Código de Defesa do Consumidor, mas sim, a todas as sentenças emanadas de ações civis públicas, tendo em vista que há previsão em ambos os diplomas legais (lei 8.078/901- art. 90 e 7.347/85 - art.21) de aplicação subsidiária.

Por fim, saliente-se que, consoante determina o art. 99 da Lei 8.078/90, havendo concursos entre créditos por danos a direitos transindividuais, “decorrentes de condenação prevista na Lei 7.347 de 24 de julho de 1985," e créditos por "indenizações pelos prejuízos individuais resultantes do mesmo evento danoso, estas terão preferência no pagamento.”

\subsection{Cumprimento de Sentença}

O cumprimento das sentenças, proferidas em ação civil pública, está subordinado ao regime do Código de Processo Civil, sendo que o rito a ser adotado dependerá da natureza da obrigação a ser cumprida. Exemplifique-se: Se for uma obrigação de fazer ou obrigação de entrega de coisa, serão observadas as disposições do art. 461 e 461 - A do CPC, "casos em que o cumprimento de sentença independe de execução autônoma, sendo promovida no âmbito da mesma relação processual em que foi proferida.” (ZAVASCKI, 2008, p. 83). Por 
sua vez, sendo uma sentença que determina a obrigação de adimplir quantia, esta será considerada título executivo, seguindo o rito proclamado pela Lei $11.232 / 2005$.

Contudo, ponderam Didier e Zanetti (2009, p. 379), que a "sentença nas ações coletivas dependerá, pois, da natureza do direito coletivo lato sensu que venha a ser afirmado."

Denota-se que o cumprimento das sentenças nas ações coletivas possui o mesmo rito das ações de natureza singular, com a peculiaridade de que, o objeto tutelado é um interesse transindividual, o que surge duas consequências importantes: quanto à legitimidade ativa e quanto ao destino a ser dado ao produto da execução.

No que tange à legitimidade ativa, segundo Zavascki (2008, p. 83), o cumprimento da sentença será requerido em regime de "substituição processual," sendo os legitimados ativos os mesmos habilitados pela Lei $7.347 / 85$, e se tal legitimado não promover o procedimento executório no prazo de 60 (sessenta) dias, o Ministério Público deverá assumir tal encargo, a teor do art. 15 da lei. Ainda, Didier e Zanetti, (2009, p. 379) preceituam que "a execução coletiva pode ser promovida por qualquer legitimado coletivo, inclusive por aquele que não tenha sido autor da ação coletiva de conhecimento."

Importante salientar que, há divergências quanto ao enquadramento da legitimidade no regime de substituição processual, legitimidade extraordinária ou autônoma. A visão depende do ângulo em que se analisa a tutela coletiva: se sob o aspecto do direito material, ou sob a perspectiva da relação jurídica (do dever), como entende Bellinetti, o qual aduz que "é preciso utilizar uma outra perspectiva de relação jurídica, mais afinada com a situação fática e suas exigências concretas.” Prossegue (BELLINETTI , 2000, p. 128).

Especialmente os conceitos de titularidade e legitimidade (ativa e passiva) devem ser vistos sob outra ótica.

A idéia de que a relação jurídica ocorre entre pessoas, devendo ter um sujeito ativo (titular do direito) e um sujeito passivo (titular do dever), perde sentido. O que há é o ordenamento impondo o dever jurídico de respeito a determinados interesses do grupo social.

Já com relação ao destino a ser dado ao produto da execução, se houver condenação em dinheiro, tal montante será revertido ao Fundo de Defesa dos Direitos Difusos, previsto pelo art. 13 da Lei 7.347/85 e Lei 9.008/1995, cujos recursos "serão utilizados na reconstituição dos bens lesados." 


\section{SENTENÇA NA AÇÃO POPULAR}

Os comentários introdutórios, declinados no item da sentença na ação civil pública, se adéquam no ato sentencial da ação popular, devido ao fato de que ambas versam sobre direitos transindividuais.

Pertinente, no entanto, fazer uma ressalva, parafraseando os dizeres de Mancuso, em sua obra específica de ação popular. $\mathrm{Na}$ visão do referido autor (MANCUSO, 2001, p. 227), "os dispositivos que na Lei 4.717/65 tratam ou aludem à sentença requerem alguma exegese para adaptá-los a sistemática processual vigente, dado que aquela lei veio a lume quando vigorava o Código de Processo Civil anterior.”

Em continuidade, o autor cita alguns exemplos de expressões oriundas do Código de Processo anterior, como, por exemplo, "absolvição de instância," abolidas pelo código hodierno.

Tais expressões não implicam em substanciais obstáculos, se efetuar a interpretação a luz das particularidades das ações coletivas, e em consonância com o código atual.

\subsection{Natureza Jurídica da Sentença que Julga Procedente a Demanda Popular}

Antes de iniciar as considerações concernentes à natureza jurídica da sentença na ação popular, importante descrever a classificação de Mancuso (2001, p. 228), que divide tais decisões em "dois tipos factíveis": as que acarretam na extinção do processo com julgamento de mérito (procedência, improcedência, ou procedência parcial), "desfechos esses que podem ter várias causas," e as que decorrem no deslinde do processo sem se adentrar no mérito, como acontece, por exemplo, na ação popular, quando há desistência pelo autor (art.9ํㅡ - ressaltando que qualquer outro cidadão ou o Ministério Público podem substituir ao autor desistente, contudo, inexiste obrigatoriedade) e, genericamente, carência de ação (art. 19).

Com relação à sentença que provoca a extinção do processo sem análise do mérito, na ação popular, Mancuso entende ter apenas o caráter declaratório “de uma dada situação processual ocorrente naquele processo,” o que não impede o ingresso de nova ação (MANCUSO, 2001, p. 235).

Quanto à natureza jurídica prevalecente nas sentenças ocorridas em ação popular, que julga procedente a demanda, o art. 11 da Lei n.. 4.717/1965 disciplina o seguinte:

A sentença que, julgando procedente a ação popular, decretar a invalidade do ato impugnado, condenará ao pagamento de perdas e danos os responsáveis pela sua 
prática e os beneficiários dele, ressalvada a ação regressiva contra os funcionários causadores do dano quando incorrerem em culpa.

Da transcrição do dispositivo acima denota-se que a sentença, na ação popular, é constitutiva e condenatória. Ressalta Silva (2007, p. 230) que "o ato inválido, por lesivo, constitui ilícito gerador de prejuízo, e justifica a atribuição da natureza condenatória reparadora à sentença que acolhe o pedido do autor."

Assim, verifica-se que o caráter condenatório, presente na sentença que julga a ação popular, é estabelecido por lei. Este efeito deve se constituir como objeto do pleito do autor, contudo, a teor do artigo 11 da lei em tela, mesmo que não seja pedido, o julgador deve consigná-lo na decisão.

Esse efeito condenatório, previsto pelo art. 11, que deve estar presente na sentença independente se for ou não requerido pela parte, é autônomo e próprio da ação popular, cujo escopo essencial é a decisão reparativa de lesão ao patrimônio público. A condenação é considerada pela lei como inerente e peculiar ao pedido de invalidação do ato lesivo.

Ainda, o disposto no art. 11 é complementado pelo dispositivo 14, o qual prescreve que o valor da lesão será apurado na execução, o que ratifica, ainda mais, a assertiva de que o efeito condenatório é próprio da demanda e não meramente secundário, acessório, "pois é incontroverso que a sentença constitutiva não é exequível, nem capaz ou necessita de execução” (SILVA, 2007, p. 231).

Dessa forma, demonstrada que a lei de ação popular prevê, expressamente, a possibilidade da condenação, independente se for pleiteado pelo autor, não há o que se falar em afronta ao art. 460 do Código de Processo Civil, cujo conteúdo prevê os limites da sentença a ser proferida pelo juiz, prescrevendo que a decisão sentencial deve estar condizente com o pedido do autor, sob pena de ser considerada ultra, extra ou cita petita. A decisão condenatória é inerente a demanda popular.

Evidenciado o caráter condenatório da sentença proferida em uma ação popular, é imperioso apontar a outra eficácia a ela inerente: a constitutiva. $\mathrm{O}$ autor, com o manejo da demanda popular, visa à recomposição do patrimônio publico, através da invalidação do ato lesivo. Assim, objetiva um provimento que anule o ato lesivo (lembrando que o ato lesivo do patrimônio público é passível de nulidade, salvo as hipóteses do art. $\left.3^{\circ}\right)$, nulidade que já existe desde o momento da formação do ato, o que significa que, tal ato nem mesmo chegou a constituir-se, e a sentença é o reconhecimento desse fato, isto é, da nulidade. Isso é importante porque a sentença que anula o ato possui efeito ex nunc (não retroage), de modo que o provimento que pronuncia a invalidade do ato nulo tem efeito retroativo ex tunc. 
Por isso, a sentença oriunda da ação popular, que decreta a nulidade do ato em debate é "constitutiva negativa" (SILVA, 2007, p. 232), porque desconstitui a situação existente, retomando o status quo ante.

\subsection{Efeitos Secundários da Sentença Condenatória}

O efeito constitutivo/negativo e condenatório são "próprios e primários da sentença, que julga procedente a demanda popular” (SILVA, 2007, p. 232). Contudo, a doutrina elenca, ainda, outros efeitos, denominados como secundários, sendo eles civis (utilização da ação regressiva, prevista pelo art. 11, onde os condenados à reparação sem culpa poderão recorrer ao judiciário para pleitear o ressarcimento dos pagamentos feitos, contra aqueles que tenham culpa no ato), administrativos (consoante art. 15, pode o processo popular criar condições objetivas para incidência de sanções administrativas, pois, se for constatada a prática de falta disciplinar, que a lei comine pena de demissão, será remetida cópia autenticada das peças necessárias a quem competir aplicar tal penalidade).

Também, há os efeitos trabalhistas (empregados subordinados a legislação trabalhista, onde constatada a pratica de falta grave que justifique a rescisão do contrato, o juiz remeterá peças autenticadas a quem compete proceder à despedida do trabalhador), e os efeitos penais, se no curso da demanda ficar comprovada a infração de normas penais.

\subsection{Sentença de Rejeição por Insuficiência de Provas}

$\mathrm{O}$ art. 18 da Lei 4.717 disciplina a sentença proferida em ação popular "julgada improcedente por insuficiência de provas," caso em que, "qualquer cidadão poderá ingressar com outra ação com idêntico fundamento, valendo-se de novas provas."

Essa sentença, nos dizeres de Silva (2007, p. 239) caracteriza-se por ser uma absolvição do demandado, "com pretensão de ser definitiva, mas que não libera o réu de futuros incômodos.” O referido autor denomina esse tipo de sentença como "decisão segundo o estado dos autos ou das alegações, sem que valha como um pronunciamento substancialmente definitivo."

Quanto à natureza dessa sentença, há controvérsias. José Afonso defende que não se trata de sentença definitiva de mérito, em que pese se caracterizar como decisão final (a rejeição só vale enquanto durar a situação, o estado dos autos, e essa demanda não fica definitivamente julgada; não faz coisa julgada material). Trata-se de uma sentença que deixa a lide em suspenso, "como uma espada de Dâmocles pendente sobre os réus.” (SILVA, 2007, p. 241). 
Nesse sentido, entende, também, Mancuso (2001, p. 247):

Cabe lembrar, outrossim, que se a causa de improcedência for a "insuficiência de prova” (e não a circunstância de a pretensão do autor ter sido infundada), a sentença de improcedência, conquanto mantenha sua natureza declaratória negativa, ensejará apenas a formação de coisa julgada formal (Lei 4.717/65, art.18).

Silva tece uma severa crítica a esse tipo de sentença, aduzindo que o juiz não decide a questão substancialmente, mas, apenas recusa a demanda sem decidi-la. Preleciona o autor que "deve-se condenar essa espécie de sentença, mormente se levarmos em conta que se deu ao MP e ao juiz ponderável poder de buscar provas suficientes para o julgamento da lide” (SILVA, 2007, p. 242).

De toda a sorte, o diploma específico da ação popular contempla a possibilidade de tal sentença, isto é, uma decisão que adentra ao mérito da causa, pois, "se o autor não se desincumbe de provar o fato constitutivo, a conseqüência é uma sentença de mérito, pela improcedência,” e que, contudo, não faz coisa julgada material, ou seja, não impede a propositura de uma nova demanda, sendo um "sistema peculiar de coisa julgada (secundum eventum litis)” (MANCUSO, 2001, p. 247), previsto pela Lei 7.347/65.

\section{SENTENÇA NO MANDADO DE SEGURANÇA COLETIVO}

O mandado de segurança coletivo está previsto pelo art. 5으. LXX da Constituição da República, o qual disciplina, especificamente, os detentores de legitimidade para o manejo de tal instrumento. Tal dispositivo veio a ser regulamentado pela Lei 12.016/2009, a qual, apesar de ser editada recentemente, vem gerando controvérsias doutrinárias.

Tal remédio constitucional possui a seguinte definição, nos dizeres de Silva (2003, p. 457):

O conceito de mandado de segurança coletivo assenta-se em dois elementos: um institucional, caracterizado pela atribuição da legitimação processual a instituições associativas, para a defesa de interesses de seus membros ou associados; outro, objetivo, consubstanciado no uso do remédio para a defesa de interesses coletivos.

A sentença, em sede de mandado de segurança coletivo, é mandamental, pois, está destinada a emitir uma ordem de fazer ou não fazer. Contudo, em tal provimento, pode-se ter os demais efeitos previstos pela doutrina (declaratório, condenatório, constitutivo e executivo). Esses são os dizeres de Arruda Alvim, citado em um artigo publicado no site http://www.ambito-juridico.com.br:

O comando mandamental, em nosso sentir, é significativo de que se agrega ao efeito da decisão uma ordem, categórica para o destinatário desta, a este mandamento submeter-se. De certa forma, se na execução, propriamente 
dita, praticam-se atos materiais substitutivos a vontade do executado, na mandamentalidade a execução de um direito depende dessa vontade, ou talvez, mais comumente de vergar e submeter a essa vontade. Nessa medida, ou diante dessa contingência, é necessário quebrar essa vontade do destinatário do mandamento. Pretender-se que alguma coisa se cumpra ou que uma ordem seja estabelecida, sem correspondente sanção, ou sem a correspondente possibilidade de sanção é manifesta ingenuidade.

Assim, denota-se que o efeito mandamental é inerente a sentença proferida no mandamus coletivo, todavia, para que alcance a efetividade em tal demanda, faz-se necessário agregar um outro atributo, relacionado ao tipo de tutela pleiteada, que a torne passível de concretizar os seus preceitos.

\section{CONCLUSÃO}

A extrema necessidade de regulamentar as ações coletivas, para que, assim, possa se consubstanciar uma efetiva tutela dos direitos de caráter supraindividuais, decorre da relevância de tais interesses, e da preponderância existente do coletivo em detrimento do individual.

Nesse sentido, os estudos doutrinários vêm instituindo novas concepções a alguns institutos processuais, com o escopo de harmonizá-los aos interesses coletivos lato sensu. Outros apanhados científicos, porém, buscam uma análise da tutela coletiva de acordo com a perspectiva da relação jurídica normativa (do dever-ser), e não do direito material, como a exemplo do já citado autor Luiz Fernando Bellinetti.

No que tange a sentença, inexistem inúmeras controvérsias, vez que as particularidades das ações coletivas se coadunam com os preceitos previstos para a sentença, nas ações individuais. Contudo, por óbvio, remanescem algumas peculiaridades, por se tratar de interesses transindividuais, características essas que as inserem em qualquer um dos efeitos (classificação quinaria). Importante relatar que, há alguns efeitos, no aspecto da ação civil pública e da ação popular, que podem ser promulgados na sentença, independente se for elemento integrante do pleito do autor. Não se trata de uma disparidade com o artigo 460 do Código de Processo Civil, que discorre os limites da sentença, mas sim, de uma particularidade, cujo fundamento é a relevância do interesse tutelado.

O Código Modelo de Processos Coletivos para a Ibero-América, e a proposta pelo CBPC-IBDP, nos seus artigos 10 e $5^{\circ}$, respectivamente, vêm disciplinando a sentença nas ações coletivas, entendendo que o pedido e a causa de pedir serão interpretados extensivamente. Trata-se de uma distinção, cujo fundamento decorre da conjuntura das ações coletivas. 
De toda sorte, qualquer inovação ou conclusão, oriunda dos estudos doutrinários ou propostas (como os projetos, por exemplo), devem ser direcionadas a instrumentalização do processo, e a eficácia da tutela postulada.

\section{REFERÊNCIAS}

BELLINETTI, Luiz Fernando. Ações coletivas - um tema a ser ainda enfrentado na reforma do processo civl brasileiro - a relação jurídica e as condições da ação nos interesses coletivos. Revista de Processo, São Paulo, v. 25, n. 98, p. 125-132, abr./jun. de 2000 .

DIDIER, Fredie Junior; ZANETI Hermes Junior. Curso de direito processual civil - processo coletivo. 4. ed. Salvador: Juspodivm, 2009. v. 4.

A INSTRUMENTALIDADE do Mandado de Seguran?Coletivo Ambiental: ensaio sobre a Jurisdi? Ambiental Coletiva. Revista Âmbito Jurídico. Disponível em: <http://www.ambito-juridico.com.br/pdfsGerados/artigos/5918.pdf>. Acesso em: 21 set. 2009.

LENZA, Pedro. Teoria geral da ação civil pública. São Paulo: Ed. Revista dos Tribunais, 2003.

MANCUSO, Rodolfo de Camargo. Ação civil pública em defesa do meio ambiente, do patrimônio cultural e dos consumidores: Lei 7347/85 e legislação complementar. 10. ed. rev. e atual. São Paulo: Ed. Revista dos Tribunais, 2007.

- Ação popular: proteção do erário, do patrimônio público, da moralidade administrativa e do meio ambiente. 4. ed. rev., atual. e ampl. São Paulo: Revista dos Tribunais, 2001.

MARINONI, Luiz Guilherme; ARENHART, Sérgio Cruz. Manual do processo do conhecimento. São Paulo: Ed. Revista dos Tribunais, 2006.

MAZZILLI, Hugo Nigro. A defesa dos interesses difusos em juízo. 14. ed. rev. ampl. e atual. São Paulo: Saraiva, 2002.

SILVA, José Afonso da. Ação Popular Constitucional: doutrina e processo. 2. ed. rev., ampl e aumentada. São Paulo: Malheiros, 2007.

. Curso de direito constitucional positivo. 22. ed. rev. e atual. São Paulo: Malheiros, 2003.

ZAVASCKI, Teori Albino. Processo coletivo: tutela de direitos coletivos e tutela coletiva de direitos. 3. ed.rev. atual. e ampl. São Paulo: Ed. Revista dos Tribunais, 2008. 
WAMBIER, Luiz Rodrigues; ALMEIDA, Flavio Renato Correia de, TALAMINI, Eduardo. Curso avançado de processo civil: teoria geral do processo de conhecimento. 9. ed. rev. atual. e ampl. São Paulo: Ed. Revista dos Tribunais, 2007.

Artigo recebido em 01/11/11 e aprovado para publicação 08/12/11

Como citar: SONNI, Indianara Pini; BELLINETTI, Luiz Fernando. Aspectos controvertidos da sentença nas ações coletivas. Scientia Iuris, Londrina, v. 15, n. 2, p. 109-124, dez. 2011. DOI: 10.5433/2178-8189.2011v15n2p109 